\title{
Experimental Investigation of an Automobile Air-Conditioning System using Integrated Brushless Direct Current Motor Rotary Compressor
}

\author{
M.F. Sukri ${ }^{1,4, a}$, M.N. Musa ${ }^{2}$, M.Y. Senawi ${ }^{1}$ and H. Nasution ${ }^{3}$ \\ ${ }^{1}$ Faculty of Mechanical Engineering, Universiti Teknologi Malaysia, 81310 Johor Bahru, Johor, Malaysia \\ ${ }^{2}$ UTM-Ocean Thermal Energy Center (UTM-OTEC), Universiti Teknologi Malaysia, Wilayah Persekutuan Kuala Lumpur, Jalan Semarak, \\ 54100 Kuala Lumpur, Malaysia \\ ${ }^{3}$ Automotive Development Centre, Universiti Teknologi Malaysia, 81310 Johor Bahru, Johor, Malaysia \\ ${ }^{4}$ Efficient Energy \& Thermal Management Research Group, Universiti Teknikal Malaysia Melaka, Hang Tuah Jaya, 76100 Durian Tunggal, \\ Melaka
}

\begin{abstract}
The present study presents an experimental investigation on the effect of condenser air inlet temperature and dimensionless parameter of $X$ on the performance of automobile air-conditioning (AAC) system using integrated brushless direct current motor-rotary compressor and electronic expansion valve. The other components of AAC system are from original component of AAC system used for medium size passenger car. The experimental results showed that the increment of the condenser air inlet temperature and $X$ caused an increase in condensing temperature, cooling capacity and compressor work, while decreasing the coefficient of performance (COP). Meanwhile, the evaporating temperature increase with the increment of condenser air inlet temperature, but decrease with decrement of $X$. In general, AAC system have to work at higher value of $X$ in order to produce more cooling capacity, thereby increment in compressor work also occurs due to energy balance. However, at higher value of $X$, the COP of the system dropped due to dominant increase in compressor power, as opposed to a rise in cooling capacity. Due to this reason, the best operation of this compressor occurs at $X=4.96$ for constant $\mathrm{T}_{5}\left(35^{\circ} \mathrm{C}\right)$, or at $\mathrm{T}_{5}=30^{\circ} \mathrm{C}$ for constant $X$ (4.96).
\end{abstract}

\section{Introduction}

An automotive air-conditioner is one of the most important accessories in typical land vehicles, which provides thermal comfort to the driver and passenger. Thermal comfort especially for drivers is crucial since road safety also improves with the comfort of the driver and a pleasant environment reduces driver fatigue [1]. However, automotive air-conditioning (AAC) system consumes second largest of energy after power train [2], thereby becoming a critical issue because of increasing concerns on energy cost, thermal comfort, greenhouse gas emissions, and vehicle performance.

Since the compressor consumes the highest amount of energy (65\%) in a typical AAC system [3], a small improvement in compressor efficiency will leads to a larger reduction in power consumption. As a result, energy is consumed efficiently, and a significant improvement in the system performance is achieved. In the other aspect, reduction in energy consumption with more efficient compressor can decreases greenhouse gas emissions. This low-carbon technology is highly relevant in the real world and an important research interest related to energy-efficient systems. Many countries, particularly developed ones, have policies to reduce greenhouse gas emissions, especially at the transportation industry. Due to these reasons, numerous studies have been conducted to improve the AAC system performance using alternative compressor of conventional belt-driven fixed capacity compressor.

Tian et al. [4] highlighted that the compressor capacity control technique by using variable capacity compressor (VCC) has been used popularly in the AAC system due to its continuous operation, better thermal comfort inside car, and lower fuel consumption. Due to these reasons, Park et al. [3], Nasution and Wan Hassan [5], Qi et al. [6], Tian et al. [7] and Alkan and Hosoz [8] conducted few studies concerning AAC system equipped with VCC, particularly in the aspect of performance as compared to AAC system with fixed capacity compressor. In general, they found that AAC system with VCC yields better performance, less in exergy destruction and good thermal comfort sensation in the rapid changing environment with less energy usage/improved fuel consumption.

In different aspect, Ooi [9] optimized rotary compressor design and theoretically reduces mechanical losses by approximately $50 \%$ and improves the COP of the compressor by more than $14 \%$. Later, a new gas compression mechanism called the "Revolving Vane" (RV) compressor was invented and theoretically shown to achieve improved mechanical, volumetric, and

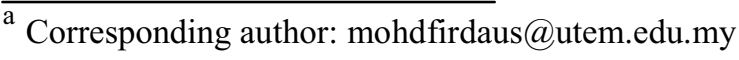


compression efficiencies compared with other existing compressor designs [10]. Further theoretical studies on this compressor have shown that friction, leakage, and discharge loss were substantially reduced in the new design, leading to significant improvements in efficiencies[10-12]. An experimental study at a shaft speed of 600-1200 rpm on the prototype of a RV compressor with air as the working fluid proved the reliability of the mechanism, achieving pressure ratios higher than $8: 1$ and more than $30 \mathrm{~h}$ of operation without any failure [13]. Further design improvements of the RV compressor with a fixed-vane significantly reduced the frictional losses by $18 \%$ to $41 \%$ and mechanical efficiency by $96 \%$ compared with the older RV compressor design [14].

Recently, Ekren et al. [15] demonstrated that direct current (DC) compressors have the potential to be used in energy-efficient refrigeration systems because these compressors do not require additional components such as a power inverter that an alternative current compressor would require. By utilizing this compressor, any problem related to the interaction of the refrigerant cycle components and the rapidly-changing operating conditions of the vehicle (speed, revolutions per minute, and so on) is solved. All types of ground vehicles are equipped with direct current batteries; thus, the authors agreed that efficient DC compressors are also among the best options to be used in an energy-efficient AAC system in future. One way of achieving an efficient DC refrigerant compressor is by integrating compressor pump with the latest brushless DC (BLDC) motor technology. The BLDC motors are microprocessor-controlled to keep the stator current in phase with the permanent magnets of the rotor, requiring less current for the same torque and therefore resulting in greater efficiency. Brushless DC motor has an excellent mechanical efficiency ranging from 85 to $90 \%$. In addition, the BLDC motor-rotary compressor can be designed for low voltage (particularly $12 \mathrm{~V}$ ) up to high voltage of up to $300 \mathrm{~V}$. Hence, it is a better choice for powering an electric refrigerant compressor.

So far, however, research of AAC system coupled with BLDC motor-rotary compressor is very limited in the publication, at least to the author's knowledge. Therefore, it is the intent of this paper to investigate the performance of BLDC motor-rotary compressor available in the market, integrated with typical vapor compression refrigeration, AAC system.

\section{Experimental set up}

\subsection{Design of experiment}

The present study aims to investigate the correlation between the condenser air inlet temperature, condenser air face velocity, compressor speed and evaporator air volumetric flowrate to the performance of AAC system equipped with BLDC motor-rotary compressor and electronic expansion valve. The actual components of heat exchangers (evaporator and condenser), internal and external fans of 1.6L Proton Wira Aaeroback passenger car are used. A SIERRA06-0982Y3 high voltage BLDC variable speed hermetic compressor and electronic expansion valve (EEV) from Danfoss, model ETS 6 - 14 are used. The selection of these two components are based on vehicle compartment cooling load model proposed by Sukri et al. [16] for typical thermophysical data of $1.6 \mathrm{~L}$ Proton Wira Aaeroback passenger car. Details of the selection process can be found in Sukri et al. [17]. The experimental test rig is mounted on an actual 1.6L Proton Wira Aeroback. Figure 1 shows the schematic diagram of the experimental test rig. Table 1 shows the model and accuracies of all test instruments.

Table 1. The accuracies of measuring instruments

\begin{tabular}{|c|c|c|}
\hline Instruments & Measurements & Accuracies \\
\hline $\begin{array}{c}\text { T-Type Thermocouple } \\
\text { with Pico TC-08 Data } \\
\text { Logger }\end{array}$ & $\begin{array}{c}\text { Refrigerant } \\
\text { and air } \\
\text { temperatures }\end{array}$ & $\pm 0.01{ }^{\circ} \mathrm{C}$ \\
\hline $\begin{array}{c}\text { AKS 32 Danfoss } \\
\text { Pressure Transducer }\end{array}$ & $\begin{array}{c}\text { Refrigerant } \\
\text { pressure }\end{array}$ & $\pm 0.01 \mathrm{bar}$ \\
\hline $\begin{array}{c}\text { 923 Fluke Air Velocity } \\
\text { Meter }\end{array}$ & Air velocity & $\pm 0.01 \mathrm{~m} / \mathrm{s}$ \\
\hline $\begin{array}{c}\text { Platon NGX Glass } \\
\text { Flowmeter }\end{array}$ & $\begin{array}{c}\text { Refrigerant } \\
\text { mass flow rate }\end{array}$ & $\pm 1 \mathrm{~g} / \mathrm{s}$ \\
\hline
\end{tabular}

The design of condenser ductwork is an open tunnel, rectangular shape and made of $20 \mathrm{~mm}$ thick insulation form (type insoform) with an overall length of $2870 \mathrm{~mm}$. In order to provide a uniform air flow through the face of the condenser, air mixer and honey comb type air flow straightener were installed upstream of the condenser coil. The air sampling tube is constructed based on BS 5141-1:1975, Specification for Air Heating and Cooling Coils - Part 1: Method of Testing for Rating of Cooling Coils [18]. The frequency converter is used to control the condenser air face velocity. Meanwhile, the original evaporator ductwork of 1.6L Proton Wira Aeroback passenger car as in Figure 2 is utilized as experimental evaporator ductwork. The evaporator air volumetric flowrate is controlled by controlling the percentage of energy input supplied to the internal fan.

The condenser air face velocity profile is measured in the condenser ductwork with cross-sectional area of 500 $\mathrm{mm} \times 500 \mathrm{~mm}$ at point 5 as in Figure 1. It is measured according to SAE International Surface Vehicle Standard 2008, Procedure for Measuring System COP of a Mobile Air Conditioning System on a Test Bench [19]. To obtain an averaged velocity, the readings have been taken by using a 923 Fluke hot-wire air velocity meter, placed successively at nine measuring points (at the same measuring plane). For each point, data is recorded for 5 minutes with averaged 10 seconds of sampling time. In total, 30 data is recorded for each point. The evaporator air volumetric flowrate is measured at point 7 as in Figure 1. At this point, the cross-sectional area of the original ductwork is $168 \mathrm{~mm}$ x $196 \mathrm{~mm}$. The methodology adopted in measuring the averaged condenser air face velocity profile is also used in measuring averaged evaporator air velocity. The averaged evaporator air volumetric flowrate, $V_{7}$ is then calculated by multiplying 


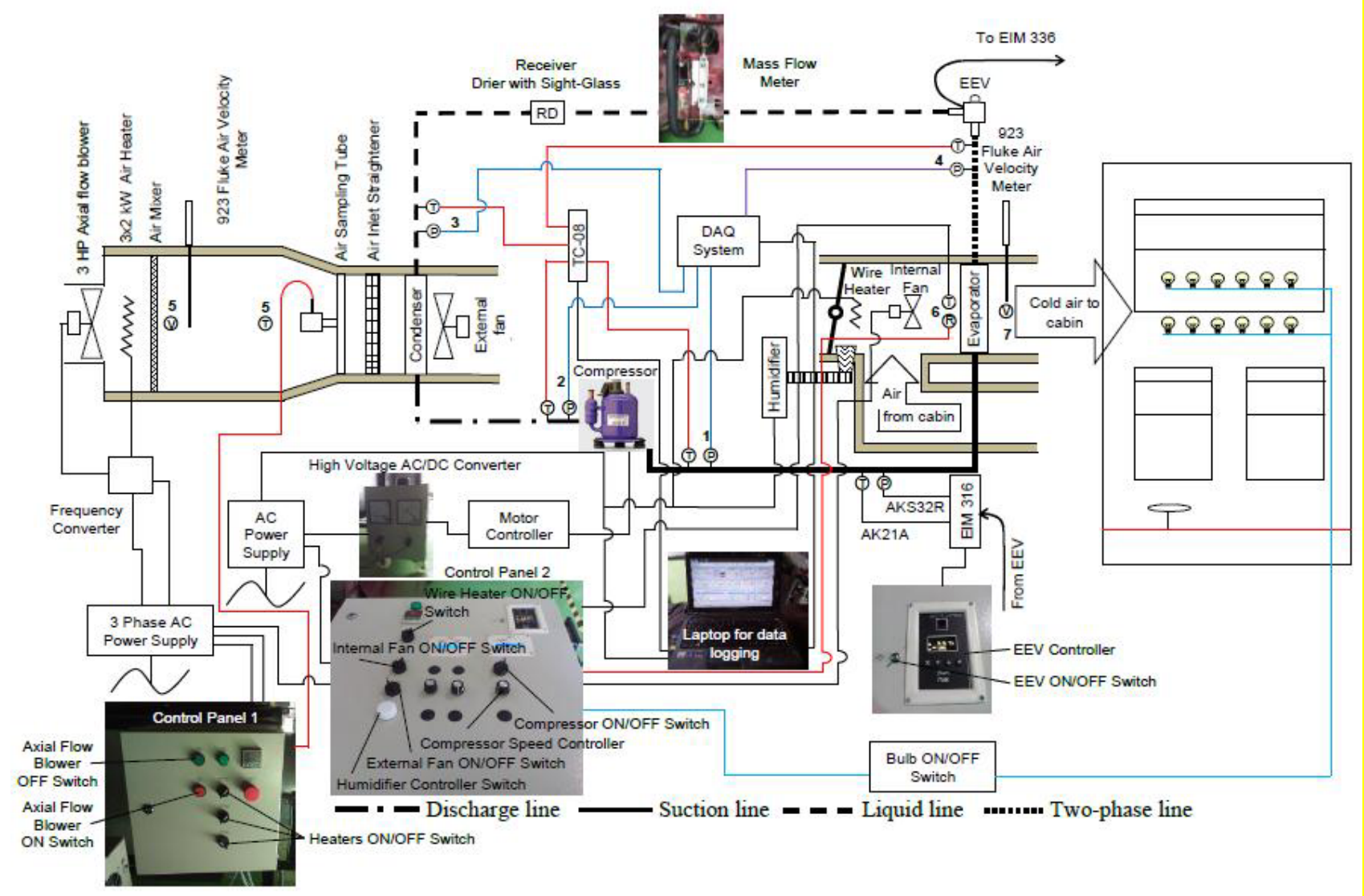

Figure 1. Schematic diagram of the experimental setup

the averaged evaporator air velocity, $v_{7}$ at point 7 with its cross-sectional area, thus:

$$
V_{7}=0.032928 v_{7} \quad\left(\mathrm{~m}^{3} / \mathrm{s}\right)
$$

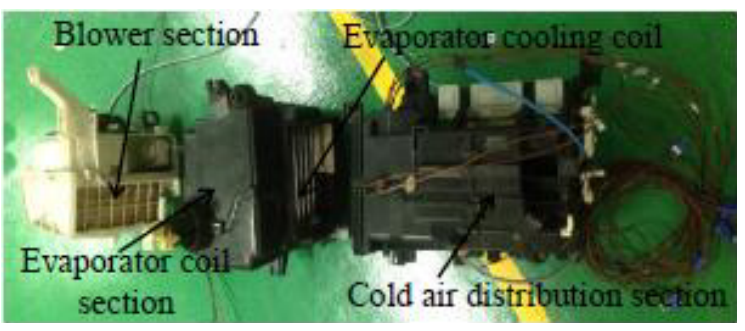

Figure 2. Evaporator ductwork

Since point sampling for each set of experimental work is time consuming, relationships are obtained between averaged condenser air face velocity and frequency of the inverter motor drive, and evaporator air volumetric flowrate with percentage of energy input. Simple linear regression are created using Microsoft Excel yields correlations as in Figure 3(a) and 3(b) for condenser and evaporator ductworks respectively. The subsequent experiments are conducted by setting an input frequency of the inverter motor drive and percentage of energy input, and the averaged air face velocity and averaged evaporator air volumetric flowrate are obtained from equations 2 and 3 respectively.

$$
\begin{gathered}
v_{5}=0.0896 f-0.17(\mathrm{~m} / \mathrm{s}) \\
V_{7}=5.9449 c+7.6091\left(\mathrm{~m}^{3} / \mathrm{h}\right)
\end{gathered}
$$

\subsection{Experimental Procedure}

The experimental work is conducted in steady state condition. The tests is conducted by varying the value of dimensionless parameter, $X\left(V_{7} N_{c}^{2} / v_{5}^{3}\right)$ and condenser air inlet temperature, $T_{5}$ at constant value of evaporator air inlet temperature, $T_{6}\left(30^{\circ} \mathrm{C}\right)$ and evaporator air inlet humidity ratio, $\phi_{6}(50 \%)$. To stabilize the airconditioning system, the system is run at least 20 minutes prior to each test before measured output variables are recorded as proposed by SAE International Surface Vehicle Standard 2008, Procedure for Measuring System COP of a Mobile Air Conditioning System on a Test Bench [19]. The output variables of refrigerant mass flow rate, $\dot{m}_{r}$, temperature and pressure at point 1 to 4 as in Figure 1 are recorded for ten minutes as proposed by SAE International Surface Vehicle Standard 2008, Procedure for Measuring System COP of a Mobile Air Conditioning System on a Test Bench [19]. The sampling time is 30 seconds. In total 20 data points is collected for each setting. 
At each experimental setting, $X$ is maintained at $4.96,11.74$ and 22.92 by controlling the value of $N_{c}, v_{5}$ and $V_{7}$ as in Table 2. At each value of $X, T_{5}$ is kept at $35^{\circ} \mathrm{C}$. Then, the experimental is repeated at $T_{5}$ of 30,35 and $40^{\circ} \mathrm{C}$, but at constant value of $X(11.74)$. During the entire experimental investigation, the $\phi_{6}$ is maintained at $50 \%$ by controlling the humidifier manually. The EEV is also manually controlled at $100 \%$ of opening degree, and the input direct current voltage to the compressor is kept at $300 \mathrm{VDC}$.

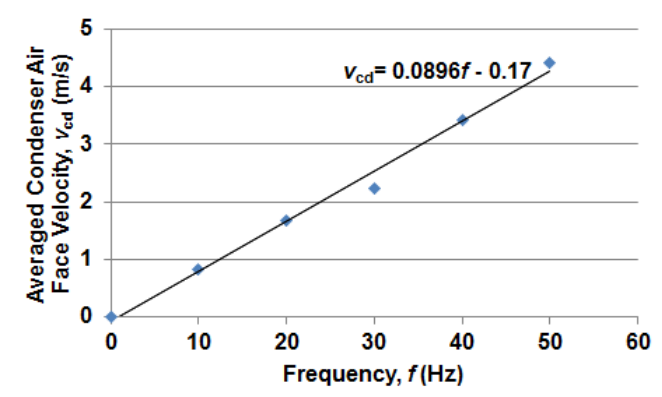

(a)

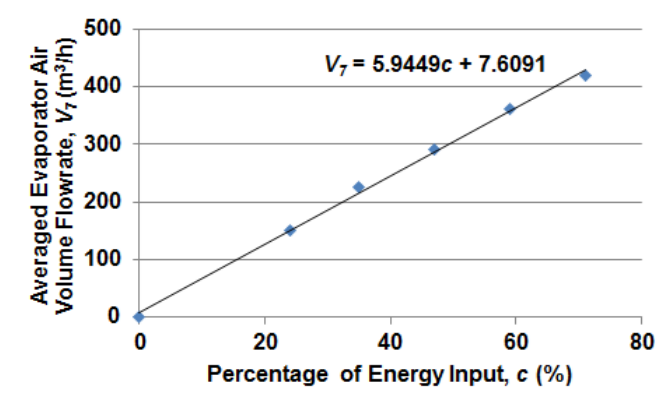

(b)

Figure 3. Liner regression between (a) averaged condenser air face velocity and frequency and (b) averaged evaporator air volumetric flowrate and percentage of energy input.

Table 2. The setting input variables during experimental work.

\begin{tabular}{|c|c|c|c|}
\hline$X=\frac{V_{7} N_{c}^{2}}{v_{5}{ }^{3}}$ & $N_{c}(\mathrm{rpm})$ & $V_{7}\left(\mathrm{~m}^{3} / \mathrm{h}\right)$ & $v_{5}(\mathrm{~m} / \mathrm{s})$ \\
\hline 4.96 & 2300 & 190 & 2.5 \\
\hline 11.74 & 3700 & 300 & 3.0 \\
\hline 22.92 & 6500 & 450 & 4.0 \\
\hline
\end{tabular}

The cooling capacity, $Q_{e}$ and compressor work, $W_{c}$ are calculated based on refrigerant enthalpy, $h$ difference between inlet and outlet of the evaporator and compressor respectively, where:

$$
\begin{aligned}
& Q_{e}=\dot{m}_{r}\left(h_{1}-h_{4}\right) \\
& W_{c}=\dot{m}_{r}\left(h_{2}-h_{1}\right)
\end{aligned}
$$

with , = 1, 2, 3, 4 .
The coefficient of performance, $C O P$ is then determined as:

$$
C O P=Q_{e} / W_{c}
$$

\section{Results and discussion}

The condensing temperature is higher at increased condenser air inlet temperature (Figure 4(a)) and $X$ (Figure 4(b)). When the condenser air inlet temperature and the value of $X$ are increased, the temperature of refrigerant discharged from the compressor will be higher cause an increased in condensing temperature. Simultaneously, the higher condensing temperature cause an increased in compressor work, as shown in Figure 5(a) and 5(b).
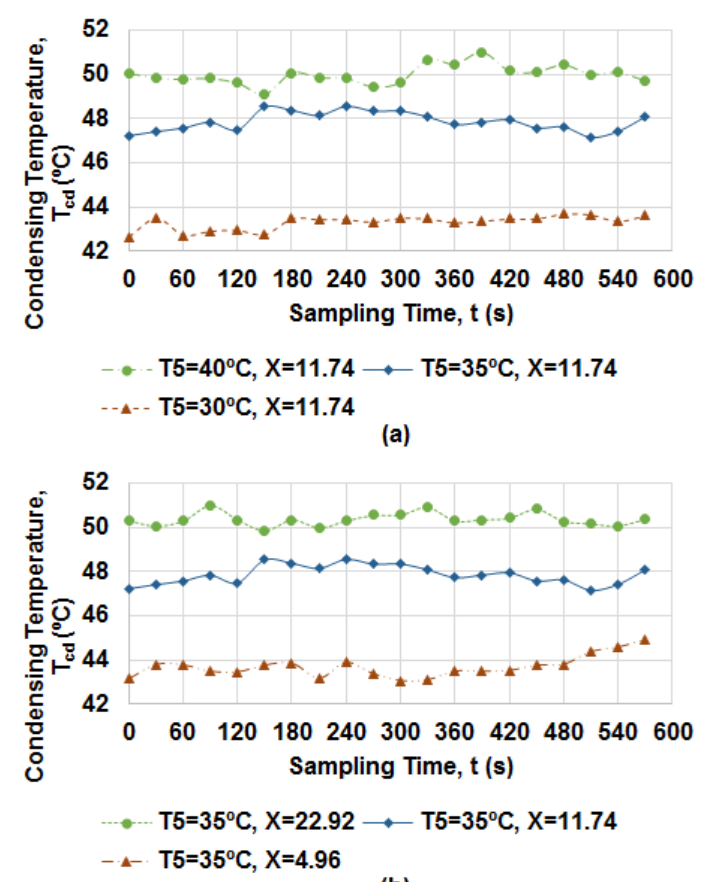

(b)

Figure 4. Condensing temperature over time (a) at constant $X=11.74$ and (b) at constant condenser air inlet temperature, $\mathrm{T}_{5}=35^{\circ} \mathrm{C}$.

Figure 6(a) and 6(b) shows the effect of cooling capacity at different condenser air inlet temperature and $X$ respectively. The decreases in the cooling capacity at lower condenser air inlet temperature as in Figure 6(a) could be due to decrease in the enthalpy difference in the evaporator caused by drop in evaporating temperature as in Figure 7(a). Therefore at constant value of $X$, the refrigeration capacity decreased with the decrement of evaporating temperature. However, Figure 6(b) and 7(b) show that at constant condenser air inlet temperature, the cooling capacity decreased with the increment of evaporating temperature. It can be clearly seen that for energy balance, at lower operating conditions of $X$ (lower of compressor speed, evaporator air volumetric flowrate and condenser air face velocity), the system produces lower cooling capacity at high evaporating temperature. 


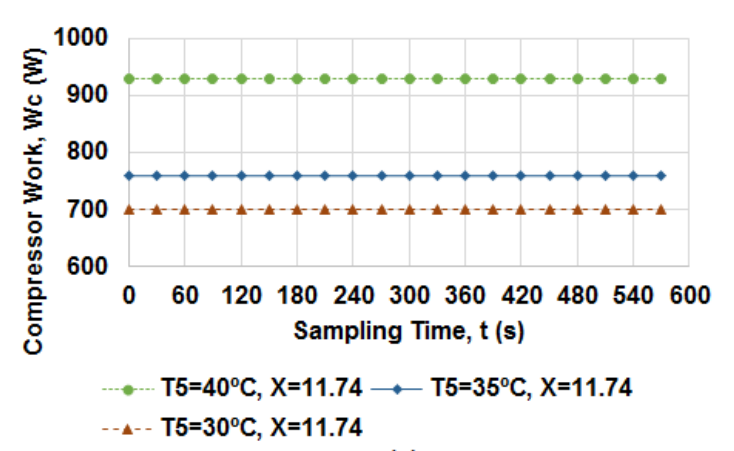

(a)

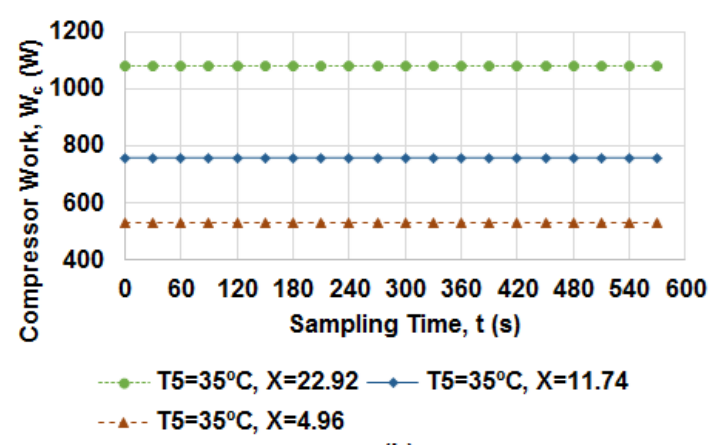

(b)

Figure 5. Compressor work over time (a) at constant $X$ $=11.74$ and $(\mathrm{b})$ at different constant condenser air inlet temperature, $\mathrm{T}_{5}=35^{\circ} \mathrm{C}$.

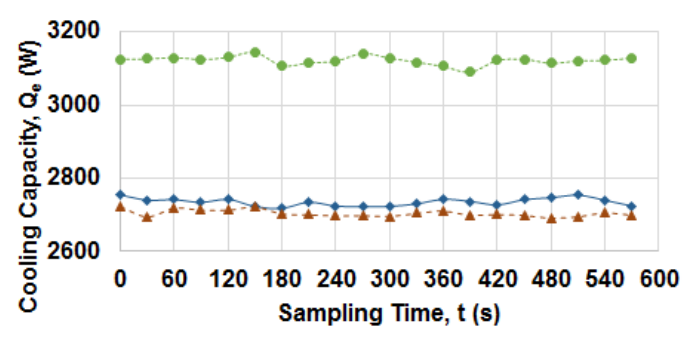

- $\mathrm{T} 5=40^{\circ} \mathrm{C}, \mathrm{X}=11.74 \longrightarrow \mathrm{T} 5=35^{\circ} \mathrm{C}, \mathrm{X}=11.74$

- $\mathrm{T} 5=30^{\circ} \mathrm{C}, \mathrm{X}=11.74$

(a)

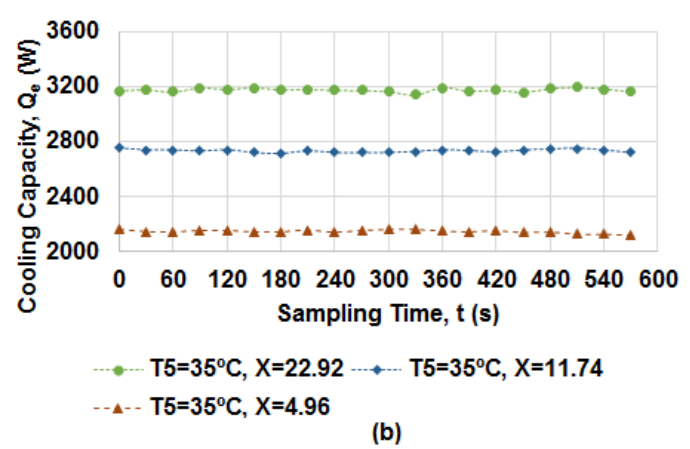

Figure 6. Cooling capacity over time (a) at constant $X=$ 11.74 and (b) at different constant condenser air inlet temperature, $\mathrm{T}_{5}=35^{\circ} \mathrm{C}$.

Figure 8(a) and 8(b) show the relationship between the $C O P$ and condenser air inlet temperature at $X$ of 11.74, and $C O P$ with $X$ at condenser air inlet temperature of $35^{\circ} \mathrm{C}$ respectively. It shows that the COP decrement is due to the increase in the condenser air inlet temperature and also with the increase of $X$. According to Eq. (6), the $C O P$ is influenced by the cooling capacity and compressor work. An increment in condenser air inlet temperature (Figure 5(a) and 6(a)) as well as in $X$ (Figure 5(b) and 6(b)) causing increase in both, cooling capacity and compressor work. Hence, a dominant increase in compressor power, as opposed to a rise in cooling capacity lead to lower $C O P$ in both cases.
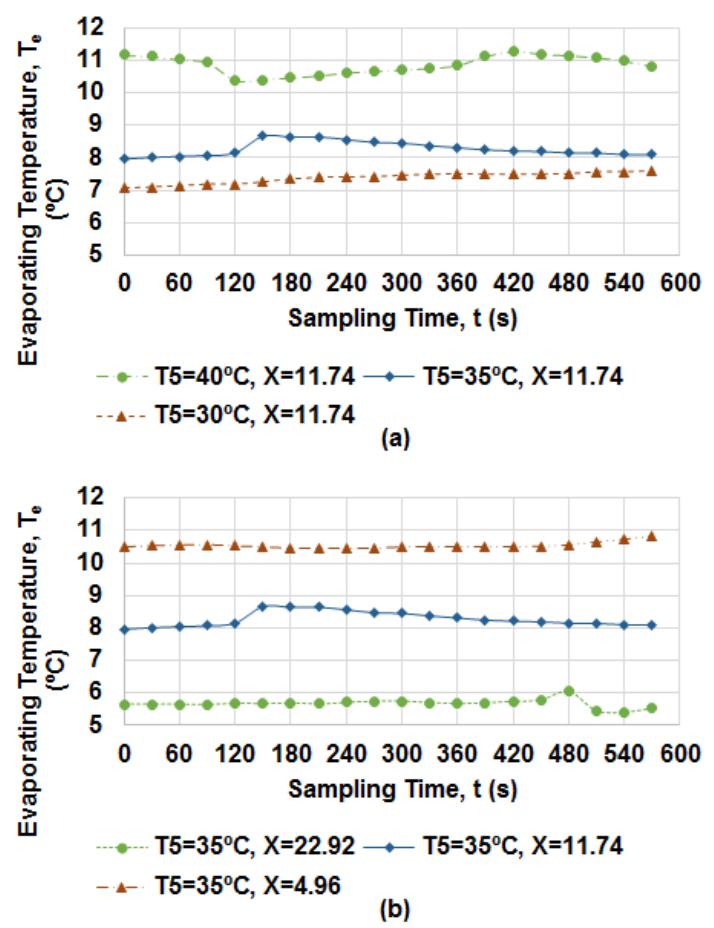

Figure 7. Evaporating temperature over time (a) at constant $\mathrm{X}=11.74$ and (b) at constant condenser air inlet temperature, $\mathrm{T}_{5}=35^{\circ} \mathrm{C}$.
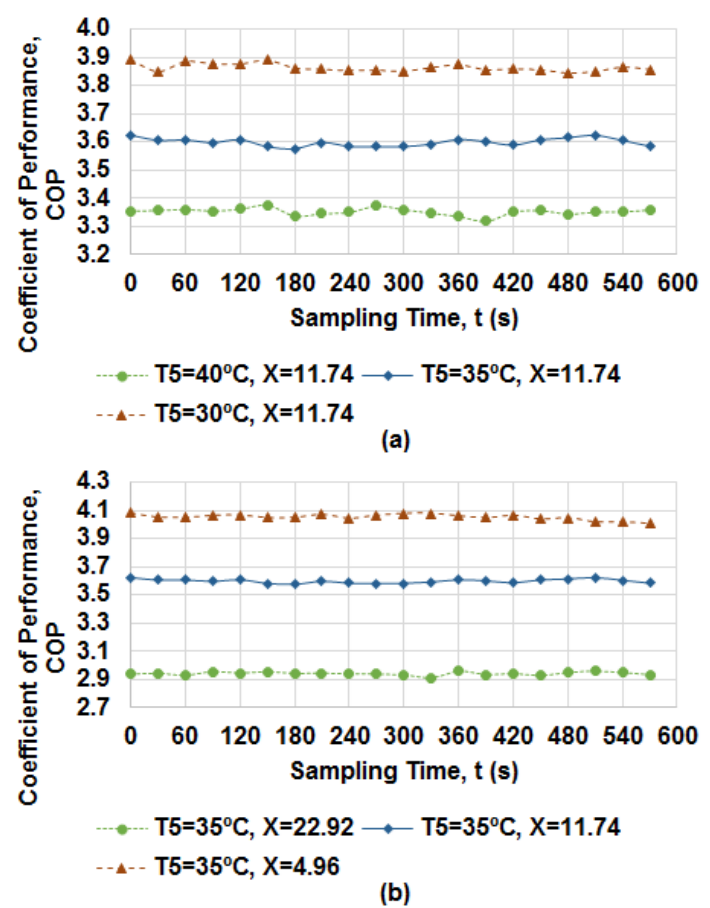

Figure 8. Coefficient of performance over time (a) at constant $X=11.74$ and (b) at constant condenser air inlet temperature, $\mathrm{T}_{5}=35^{\circ} \mathrm{C}$. 


\section{Conclusions}

The present study provides experimental result of an automobile air-conditioning system equipped with integrated BLDC motor-rotary compressor and EEV. The results of this study showed that the increment of the condenser air inlet temperature and value of $X$ respectively caused an increase in condensing temperature, cooling capacity and compressor work, while decreasing the $C O P$. However, the evaporating temperature increases with the increment of condenser air inlet temperature, but decrease with decrement of $X$. In general, AAC system have to work at higher value of $X$, particularly at high compressor speed in order to produce more cooling capacity, thereby increment in compressor work also occurs due to energy balance. However, at higher value of $X$, the $C O P$ of the system dropped due to dominant increase in compressor power, as opposed to a rise in cooling capacity. As a result, the best operation of this compressor occurs at $X=4.96$ for constant $\mathrm{T}_{5}$ $\left(35^{\circ} \mathrm{C}\right)$ or at $\mathrm{T}_{5}=30^{\circ} \mathrm{C}$ for constant $X(4.96)$.

\section{Acknowledgements}

The authors would like to be obliged to Universiti Teknologi Malaysia, Universiti Teknikal Malaysia Melaka and Ministry of Education Malaysia for providing laboratory facilities and all financial assistances, especially under project no. Q.J130000.2424.00G41.

\section{References}

1. M. Konz, A generic simulation of energy consumption of automobile air conditioning systems (M Tech Eng Thesis. Nelson Mandela Metropolitan University, 2007).

2. M.A. Roscher, W. Leidholdt, J. Trepte, Int J Elec Power 37(1), 126-130 (2012).

3. S.K. Park, H. Kim, H. Ahn, H.S. Park, SAE Technical Paper, 2006-01-0164 (2006).

4. C. Tian, H. Xu, L. Zhang, X. Li, Appl Therm Eng 29, 2824-2831 (2009).

5. H. Nasution, M.N. Wan Hassan, Clean Techn Environ Policy 8, 105-111 (2006).

6. Z. Qi, J. Chen, Z. Chen, W. Hu, B. He, Appl Therm Eng. 27, 927-933 (2007).

7. C. Tian, H. Xu, X. Li, Y. Liao Y. Appl Therm Eng. 27, 1868-1875 (2007).

8. A. Alkan, M. Hosoz. Int J Refrig 33(3), 487-495 (2010).

9. K.T. Ooi, Appl Therm Eng. 25(5-6), 813-829 (2005).

10. Y.L. Teh, K.T. Ooi, Int J of Refrig 32(5), 1092-1102 (2009).

11. Y.L. Teh, K.T. Ooi, Int J Refrig 32(5), 1103-1111 (2009).

12. Y.L. Teh, K.T. Ooi, Int J Refrig 32, 945-920 (2009)

13. Y.L. Teh, K.T. Ooi, Appl Therm Eng 29(14-15), 3235-3245 (2009).
14. K.M. Tan, K.T. Ooi, Int J Refrig 34(8), 1980-1988 (2011).

15. O. Ekren, S. Celik, B. Noble, R. Krauss, Int J Refrig 36(3), 745-757 (2013).

16. M.F. Sukri, M.N. Musa, M.Y. Senawi, H. Nasution, 7th International Meeting on Advances In Thermofluids (7th IMAT) (Swiss-Garden Hotel and Residences, Kuala Lumpur Malaysia, Nov 2014).

17. M.F. Sukri, M.N. Musa, K. Sumeru, S. Sodiya, JAMT 8(2), 39-49 (2014).

18. BS 5141-1:1975, Specification for Air Heating and Cooling Coils - Part 1: Method of Testing for Rating of Cooling Coils (1975).

19. SAE International Surface Vehicle Standard, Procedure for Measuring System COP of a Mobile Air Conditioning System on a Test Bench (2008). 